\title{
Uniform Delivered Pricing is Essentially Freight Absorption Pricing : A Theoretical Model with Simulation
}

\author{
Po-Sheng Ko \\ Dept. of Public Finance and Taxation \\ National Kaohsiung University of Applied Sciences
}

\begin{abstract}
The uniform delivered price is the price contains mill price and transportation cost. Although the firms bear the transportation cost, practically the firms would pass all or part of transportation cost through to consumers. The research finds that, as the demand curve slopes downward or there exists competitors or potential competitors, the U.D.P. firms neither can pass all of transportation cost through to consumers, and nor bear all of it. Furthermore, the Löschian firms are able to pass larger portion of transportation cost through to consumers than the Hotelling-Smithies competition firms do. Therefore, the U.D.P. is essentially Freight Absorption Pricing which is another spatial pricing policy used by the firms.
\end{abstract}

Keywords: spatial competition, uniform delivered pricing, Hotelling-Smithies model, Löschian model

\section{Introduction}

Uniform delivered pricing (U.D.P.) policy is that firms set the same delivered price at all points in space. Under this policy the firms pay the transportation cost instead. Greenhut et al. (1980) and Greenhut (1981) observed that about a quarter of the firms in the US charged uniform delivered price. In practice, the use of U.D.P. for final or intermediate products seems rather common in free-market economy. However, very few theoretical attempts have been made to present formally the possible free entry competitive equilibria under U.D.P.. Furthermore, although urban location of firms is better analyzed by two-dimensional space, it is usually examined by one-dimensional space in the literature due to mathematical tractability. There is no doubt that one-dimensional analysis has the undeniable advantage of simplicity. ${ }^{1} \mathrm{Ko}(2005)$

\footnotetext{
${ }^{1}$ See Gronberg and Meyer(1981), Schuler and Hobbs(1982), Balcer(1983), de Palma et al.(1986), de palma et al.(1987), Anderson et al.(1989),
}

developed a two-dimensional spatial competition model of firms under U.D.P.. As to the topic on price pass-through, there is no research found in the literature on spatial competition.

Although the U.D.P. firms set a uniform delivered price to all customers within certain area, the firms would pass part of transportation cost through to consumers and absorb the rest themselves. I refer to this behavior as price pass-through. Thus, this research will prove and demonstrate that the U.D.P. is essentially Freight Absorption Pricing by following and extending Ko's(2005) model.

\section{The Theoretical Model}

The basic notation and assumptions attempt to follow that used by Ko (2005).

ASSUMPTION 1: There is a single commodity produced with the same cost function for all firms. The cost function is $C=f+c X$, where $X=$ output; $C=$ production cost; $f=$ fixed cost; $c=$ marginal cost.

ASSUMPTION 2: The firms bear the transportation cost. The uniform delivered price $P$ is as follow: $P=$ $m+t u$, where $m=$ mill price; $u=$ distance between the firm and the consumer; $t=$ transportation cost per unit distance.

ASSUMPTION 3: Potential customers are uniformly distributed over a unbounded, two-dimensional market. Let $\mathrm{D}$ be the density of distributed customers.

ASSUMPTION 4: All consumers are identical and have a demand curve for $X$ that is linear in delivered price $P . \quad X=a-b P=a-b(m+t u) \quad a, b>0$

ASSUMPTION 5: Firms are assumed to maximize profits and set a uniform delivered price $P$.

ASSUPTIOM 6: Firms continue to enter or exit until profits for all firms are equal to zero.

In addition, I concern the reaction of a firm to a change in competitor's price.

ASSUMPTION 7a: Löschian competition - each firm assumes its market area to be fixed, that is $d r / d p$

Beckmann(1976), Kou et al.(1993), Beckmann and Ingene(1976), Greenhut et al.(1986) and Hsu(1983). 
$=0$, where $r$ is the radius of firm's market area. The individual firm believes that its competition will change its price by an amount equal to one's own price change. That is $\partial P_{j} / \partial P_{i}=1$.

ASSUMPTION 7b: Hotelling-Smithies (H-S) competition - that the individual firm believes hat its competition does not change its price. That is $\partial P_{j} / \partial P=0$.

ASSUMPTION 8: overlapping market area is possible under U.D.P. - firms can serve all of consumers in the market area, and price to the customer is the same for each firm.

ASSUMPTION 9: For a U.D.P. firm, theoretically, transportation cost by definition is

$T D C=D * \int_{0}^{r} t * u *(a-b p) * 2 \pi u d u$

TDC is the transportation cost that the firm needs to spend to deliver its products to the consumers. and the total demand will be .

$X=D * \int_{0}^{r}(a-b * p) * 2 \pi u d u$

Therefore, the transportation cost the firm actually bears is total revenue minus total fixed costs and total variable costs and firm's profits, is expressed as $R D C=P^{*} X-F-C^{*} X-Y$, where $P^{*} X$ is the firm's total revenue, $F$ is the fixed cost, and $C^{*} X$ is the total variable cost. Hence (TDC-RDC) is the portion of transportation cost that the firm passes through to consumers. This research defines and refers the ratio of the portion consumer bears to total transportation cost , $(T D C-R D C) / T D C$, as the firm's ability of price pass-through.

Three situations regarding the radius of each firm's market area are possible. The first, the firms' market areas do not overlap. In this case, each firm can act as a monopolist. The solution to this monopoly problem in well known and need not be detailed here. The second, the desired market areas overlap in the first stage. Owing to competition the firms' market areas finally do not overlap, but are tangent to each other. Any two neighboring firms locate a distance $u$ apart, and desire to serve a distance (radius) $\mathrm{u} / 2$. However, the consumers in the areas outside of firms' market areas (circles) can not be served. The third, the firms' desired market areas overlap and all of consumers in the market can be served by the firms, as Figure 1 shows.

From Assumption 6, profits will be zero in longrun equilibrium. This implies that

$$
\begin{aligned}
& Y=D^{*} \int_{0}^{r}(p-t h-c)(a-b p) * 2 \pi h d h-F \ldots \ldots(1) \\
& Y=\pi D(a-b p)\left[(p-c) r^{2}-\frac{2 t r^{3}}{3}\right]-F=0 \ldots \ldots \ldots \ldots . .(2)
\end{aligned}
$$

For each level of fixed cost, one can set this function equal to zero and obtain a set of U.D.P. $p$ and distance $r$ to serve, which yield zero profits to firms. This curve is shown in Figure 2 for three levels of fixed cost and is designated the zero profit locus (ZPL). A portion of the $\mathrm{ZPL}$ associated with fixed cost level $\mathrm{F}_{0}$, $F_{1}$, and $F_{2}$ are also shown assuming $F_{0}>F_{1}>F_{2}$. The curve collapses around the point $\mathrm{M}$ as fixed cost rises. The point $M$ also defines the maximum possible extent of the market and the highest price the firm would set.

Besides, in long-run equilibrium it is not possible that the mill price $m$ is less than marginal cost $c$. This implies that

$\because m \geq c \quad \therefore m+t u \geq c+t u$ and $p=m+t u \quad \therefore$

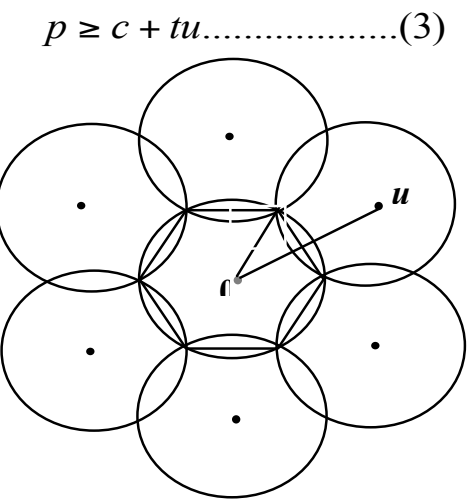

Figure 1 : The desired market areas overlap.

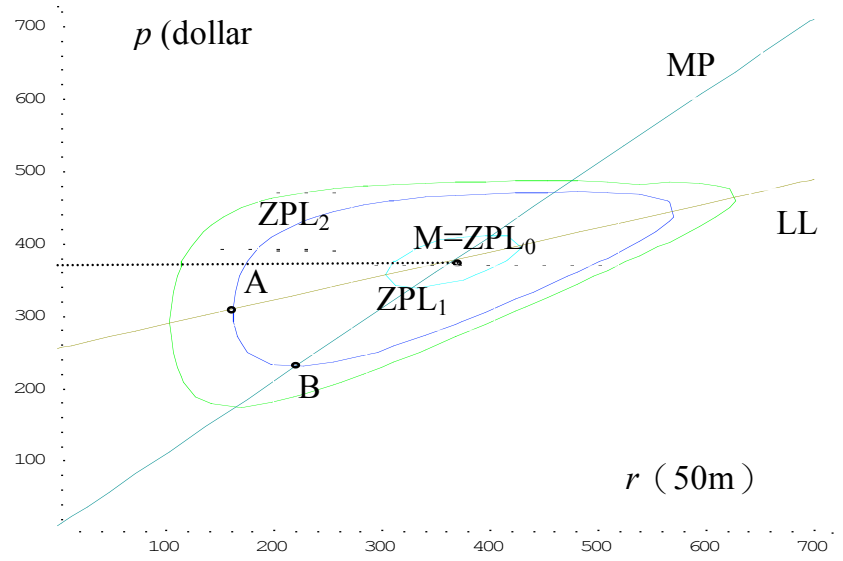

Figure $2: a=50 、 b=0.1 、 c=10 、 t=1 、 D=1$ 、 $F_{0}=6.367 \times 10^{8} 、 F_{1}=6 \times 10^{8}$ and $F_{2}=3 \times 10^{8}$

Three models are discussed in the following:

\subsection{The Löschian competition without overlapping markets}

The first and necessary condition for profitmaximizing is that

$\frac{d Y}{d p}=0=r^{2}\left(a-2 b p+b c+\frac{2 b t r}{3}\right)+2(a-b p)\left[(p-c) r-t r^{2}\right] \cdot \frac{d r}{d p}$

Because of Löschian competition, $d Y / d p=0$, then it

becomes $r^{2}\left(a-2 b p+b c+\frac{2 b t r}{3}\right)=0$

$\therefore p=\frac{a}{2 b}+\frac{c}{2}+\frac{t r}{3}$ 
The equation (4) is designated the line LL shown in Figure 2. Therefore, the point A, $\left(r_{L}, p_{L}\right)$, the intersection of the line LL with the $\mathrm{ZPL}_{2}$ represents the long-run equilibrium in which free entry or exit occurs to alter $r$ until zero profits are earned by the Löschian firms. ${ }^{2}$

\subsection{The Hotelling-Smithies competition without overlapping markets}

It is assumed that the individual firm believes that its competition either does not change its price. Under this circumstance, a firm can resolve the problem of overlapping desired market areas by simply cutting its price by any amount. This price change, no matter how small, is sufficient to allow the firm to capture the disputed market area. Assuming all firms believe this to be true, equilibrium can only occur when all firm's prices have fallen to the point where their desired market areas no longer overlap. That is price must fall until $c+t u$. The graphic representation of $p=c+t r, r=u / 2$, which is designated the line MP, is shown in Figure 2. Hence, the point $\mathrm{B},\left(r_{H-S}, p_{H-S}\right)$, the intersection of the line $\mathrm{MP}$ with the $\mathrm{ZPL}_{2}$ represents the long-run equilibrium in which free entry or exit occurs to alter $r$ until zero profits are earned by the Hotelling-Smithies competition firms. ${ }^{3}$

\subsection{The spatial competition with overlapping markets}

As Figure 2 shows, the firms' desired market areas overlap and all of consumers can be served by the firms. Assuming that the area in the disputed market is shared by two neighboring firms and for simplification the consumers will choose the firm with which is close to them to do business, the representative firm's market area in long-run equilibrium will be a hexagonal market area. Then, the representative firm's profits function becomes

$$
\begin{aligned}
Y^{c}= & 12 D \int_{0}^{\frac{u}{2}} \int_{0}^{\frac{\pi}{6}}(P-t * r * \operatorname{Sec}[\theta]-c)(a-b p) d \theta d r-F \\
& =D(a-b p)\left(p \pi u-c \pi u-\frac{t^{*} u^{2}}{4} * \ln [27]-F \ldots \ldots \ldots . .(5)\right.
\end{aligned}
$$

The first condition of equilibrium is expressed as following :

\footnotetext{
${ }^{2}$ By simulating with a software of Mathematica, the Löschian equilibrium is that $P_{L}=308.903$ and $r_{L}=$ 161.708 .

${ }^{3}$ By simulating, the H-S competition is that $P_{H-S}=229.6$ and $r_{H-S}=219.6$.
}

$D(a-b p)\left(p \pi u-c \pi u-\frac{t^{*} u^{2}}{4} * \ln [27]-F=0 \ldots(6)\right.$

The zero profit locus $\left(Z P L_{F i}^{C}\right)$ is shown in Figure 3.

The assumption of overlapping market areas holds if and only if each firm serves to a distance $(p-c) / t$ which

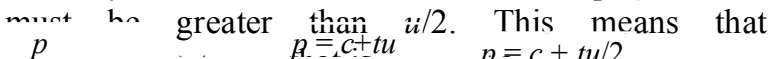

500

$P_{300}$ 200

Figure $3: \mathrm{a}=50, \mathrm{~b}=0.1, \mathrm{c}=10, \mathrm{t}=1, \mathrm{D}=1, \quad \mathrm{~F}_{0}=5.219 \times 10^{6}$, $\mathrm{F}_{1}=4.2 \times 10^{6}, \mathrm{~F}_{2}=3 \times 10^{6}$

Two models with overlapping markets are considered: one involving Löschian conjecture assumption and the other involving price competition. First, under the assumption of Löschian competition with overlapping markets, the condition for profit maximization gives

$$
\begin{gathered}
D(a-b p) \pi u-b D\left(p \pi u-c \pi u-\frac{t^{*} u^{2}}{4} * \ln [27]=0\right. \\
\therefore p=\frac{a}{2 b}+\frac{c}{2}+\frac{t u}{8 \pi} * \ln [2] \ldots \ldots \ldots \ldots \ldots . . .
\end{gathered}
$$

The equation (7) is designated the line CC in Figure 3. The point $\mathrm{C}$, the intersection of the line $\mathrm{CC}$ with the $Z P L_{F_{1}}^{C}$, represents the long-run equilibrium by the Löschian firms with overlapping markets. ${ }^{4}$

Next we consider the price competition model with overlapping markets. As mentioned above, in the case that the firms' desired market areas overlap, it must be that $p>c+t u / 2$. Price $p$ depends upon the degree of price competition between firms. Price $P$ approaches to $c+t u / 2$ as price-competing increases. This implies that the equilibrium with overlapping markets lie between point $\mathrm{C}$ and $\mathrm{D}$ in Figure $3 .^{5}$ The equilibrium will occur at point $\mathrm{C}$ as the firms collude. Therefore, unless the firms collude, the equilibrium

\footnotetext{
${ }^{4}$ By simulating, the numerical solution to equilibrium is that $P_{c}=297.9$ and $u_{c}=327.4$.

${ }^{5}$ The point $\mathrm{D}$ in Figure 3 is as same as point $\mathrm{B}$ in Figure 2. By simulating, $p_{\mathrm{D}}=244.6$ and $u_{\mathrm{D}}=469.3$.
} 
will approach but not reach to point $\mathrm{D}$ as the degree of price competition increases.

\subsection{Price Pass-through by U.D.P. Firms}

From Assumption 9, the research defines and refers the ratio of the part consumer bears to total transportation cost, $(T D C-R D C) / T D C$, as the firm's ability of price pass-through.

As a result, the ratio at the long-run equilibrium point $\mathrm{A}$ in the the Löschian model is 0.835 which is higher than 0.615 at point B in the Hotelling-Smithies competition model. This finding implies that the Löschian firms are able to pass larger part of transportation cost on to consumers than the Hotelling-Smithies competition firms do. The reason is that Löschian firms act as a cartel because of collusion, therefore the firms have higher market power to pass through than the Hotelling-Smithies competition firms do. Nevertheless, even the collusive firms can not pass all of transportation cost through to consumers.

Besides, the research also finds that the ratio approaches increasingly to 0.835 and 0.615 respectively as equilibrium approaches toward A or B from $\mathrm{M}$. The reason might be that the firm's profits will decrease because of new entry, therefore the ability and willingness of absorbing the transportation cost decrease. This also might implies that as radius $r$ is large, the firm intends to bear larger part of transportation cost to compete with the other firms in order to occupy the larger market.

\section{Conclusions}

The uniform delivered price is the price contains mill price and transportation cost. Although the firms bear the transportation cost, practically the firms would pass all or portion of transportation cost through to consumers. However, the question we are concerning is how much of transportation cost can be passed on to consumers. Theoretically, unless the demand is perfectly inelastic and there is no substitutes in the market, the firms are not able to pass all of transportation cost on to consumers.

The research finds that, as the demand curve slopes downward or there exists competitors or potential competitors, the U.D.P. firms neither can pass all of transportation cost through to consumers, and nor bear all of it. Furthermore, the Löschian firms are able to pass larger portion of transportation cost through to consumers than the Hotelling-Smithies competition firms do. Therefore, the U.D.P. is essentially Freight Absorption Pricing which is another spatial pricing policy used by the firms.

\section{References}

[1] S.P. Anderson, A. de Palma and J.-F. Thisse, “ Spatial Price Policies Reconsidered," Journal of Industrial Economics, 38(1): pp.1-18,1989.

[2] Y. Balcer, "F.O.B. Pricing versus Uniform Delivered Pricing: A Welfare Analysis in a Stochastic Environment ," Journal of Economic Theory, 30(1), pp.54-73, 1983

[3] M. Beckmann, " Spatial Price Policies Revisited ", Bell Journal of Economics, 7(2), pp. 619-630, 1976.

[4] M. Beckmann and C. A. Ingene, "The Profit Equivalence of Mill and Uniform Prices ," Regional Science and Urban Economics, 6(6), pp.327-329, 1976.

[5] A. de Palma, J.P. Pontes and J.-F. Thisse, "Spatial Competition under Uniform Delivered Pricing ," Regional Science and Urban Economics, 17(3), pp.441-449, 1987.

[6] A. de Palma, M. Labbe and J.-F. Thisse, "On The Existence of Price Equilibria under Mill and Uniform Delivered Price Policies ," in G. Norman (ed.), Spatial Pricing and Differentiated Markets, London:Pion Press, 1986.

[7] J. Greenhut, M.L. Greenhut and S. Li, 1980. "Spatial Pricing Patterns in the United States," Quarterly Journal of Economics, 94(2), pp.329350, 1980.

[8] M.L. Greenhut, "Spatial Pricing in the United States, West Germany and Japan ," Economica, 48(189), pp.79-86, 1981.

[9] M.L. Greenhut, C.C. Mai and G. Norman, "Impacts on Optimum Location of Different Pricing Strategies, Market Structure and Customer Distribution over Space," Regional Science and Urban Economics, 16(3), pp.329$351,1986$.

[10]T. Gronberg and J. Meyer, "Competition Equilibrium Uniform Delivered Pricing Models," American Economic Review, 71(4), pp.758-763, 1981.

[11] S.K. Hsu, "Pricing Rules of a Cooperative Firm in a Spatial Market," Academia Economic Paper, 11(1), pp.29-143, 1983.(in Chinese)

[12]P.S. Ko, "A Theoretical Model for Pricing Analysis of Firms Under Uniform Delivered Pricing," Journal of Management, 22(2), pp. 227 240, 2005.(in Chenese)

[13] H.I. Kou, C.C. Mai and H. Hwang, "Economic Analysis of Spatial Policies in Input Market," Taiwan Economic Review, 21(1), pp.79-98, 1993.(in Chinese)

[14]R. Schuler and B.F. Hobbs, "Spatial Price Duopoly under Uniform Delivered Pricing," 
Journal of Industrial Economics, 31(1/2), pp.175181,1982 . 